\title{
Ecos de sociedad 2015
}

Society notes

\author{
María Bermúdez Ramos
}

Secretaria de la SOGAMI

De nuevo este año me toca hacer un ejercicio de memoria para intentar plasmar en una carilla todo aquello que ha ocurrido en relación a nuestra Sociedad en los últimos 12 meses, cosa que adelanto será sumamente difícil. Si bien el año pasado iniciaba esta sección con un tono pesimista sobre el porvenir del sistema sanitario público, esta vez quiero despedirme de la Secretaría de la SOGA$\mathrm{MI}$ con una visión diferente hacia el futuro. $\mathrm{Y}$ es que como un buen médico cercano me recuerda a diario, la esperanza es la base del pensamiento positivo. Quiero hacer un canto de ánimo y felicitación a todos aquellos compañeros que, poco a poco, más que "encontrar su sitio" se han ido haciendo uno donde han podido; a los que han tenido que sacrificar un poquito de su vida personal para continuar ejerciendo la Medicina, mejorando así la vida de otros muchos; a todos aquellos que diariamente se "echan a la carretera" con un café y vuelven tarde a sus casas porque regalan horas a sus pacientes y a su profesión. A todos esos "médicos atentos" (documental muy recomendable por cierto), enhorabuena.

Todos nosotros constituimos una sociedad amplia y heterogénea aunque unida y sólida. La SOGAMI continúa "funcionando" de forma efectiva y eficiente. $Y$ aunque no nos quedaba duda alguna de ello, sin esperarlo y sin recurrir a nada extraordinario para conseguirlo (tan sólo ser lo que somos), esa proyección exterior de solidez nos llegó en forma de reconocimiento público a finales de 2014 , cuando la compañía editorial Sanitaria 2000 nos nombró mejor Sociedad Científica en los Premios a la Sanidad en Galicia.

Lo cierto es que una sociedad sólida y consagrada como la nuestra debe ser accesible y transparente, de ahí que la página web www.meiga. info siga proporcionando al público en general y a los socios en particular, contenido científico y de información propia, haciendo públicas las actas de sus reuniones y los nombres de los beneficiarios de becas y premios. La Sociedad debe promocionar y facilitar el acceso a esta información, y por ello recientemente se ha iniciado el envío de newsletters con titulares relevantes y accesos directos a webs de interés. Ha de tener un órgano de expresión y promover la producción científica; como tal, Galicia Clínica (cuyo archivo histórico estará disponible próximamente gracias a la Fundación Barrié) sigue llegando trimestralmente a nuestros buzones, manteniendo los originales e incorporando poco a poco el idioma de Shakespeare en sus páginas. De forma imprescindible una sociedad ha de ser dinámica, promoviendo nuevos proyectos como la creación del grupo de trabajo de enfermedad tromboembólica propulsado desde el Hospital Lucus Augusti. Este grupo de trabajo se une a los ya existentes dentro de la SOGAMI, entre los que destaca por su actividad el de Riesgo Vascular (GRIVA). De modo espontáneo y con la Sociedad como mero catalizador, los residentes se han reunido en grupos de trabajo con vistas a la investigación sobre enfermedades concretas, cuyos resultados en forma de publicación ya empiezan a vislumbrarse. Finalmente, una Sociedad ejemplar debe adaptarse a las nuevas tecnologías -de ahí que mantengamos la realización de la mayoría de nuestras reuniones vía online y seamos visibles a través de Facebook y Twitter- eso sí, sin olvidar por completo la tradición. Y siguiendo esa tradición, la reunión de ex-presidentes de la Sociedad, donde frecuentemente se gestan muchas de las iniciativas que posteriormente se llevan a cabo, tuvo lugar en Santiago.

Pero lo que sin duda define a una (o al menos a nuestra) sociedad, es que sus miembros sientan que forman parte de ella. Es probable que sobre esto se asiente el éxito de nuestro congreso anual, que este año se celebró en Sanxenxo en fechas 5 y 6 de Junio, congregando a más de un centenar de profesionales. Nuestras más sinceras felicitaciones al Dr. de Lis (al que recientemente han intentado jubilar) y al resto de los miembros de los comités organizador y científico por la gran participación y por el espectro de contenidos tratados durante las jornadas. De nuevo, como en reuniones anteriores, ponentes de diversas procedencias tanto a nivel geográfico como hospitalario (ramas médicas y quirúrgicas) nos hicieron disfrutar de mesas de lo más variadas. Se abordaron temas clásicos desde 
una nueva perspectiva, como la cirugía bariátrica y su repercusión en el manejo de la diabetes mellitus, la anticoagulación en el paciente oncológico con enfermedad tromboembólica o, como colofón, un tema de la más candente actualidad: el uso de los nuevos antivirales de acción directa en el tratamiento de la hepatitis C crónica. Una completa revisión del tema, con cierre del Dr. Félix Rubial, gerente del C.H. Universitario de Vigo y exDirector Xeral de Asistencia Sanitaria. En cuanto a las comunicaciones, la gran cantidad y calidad de trabajos recibidos puso de manifiesto el interés científico de nuestra sociedad. Más de una decena fueron presentadas oralmente, alzándose con el primer premio la Dra. Velo García, tras exponer los resultados de una cohorte del registro RIETE en relación a la anticoagulación en pacientes mayores; el segundo premio fue compartido entre los Dres. Domínguez Rodríguez y Meijide y la ganadora de la mejor comunicación póster fue la Dra. Latorre Diez con un trabajo sobre amiloidosis.

Coincidiendo con la Reunión anual, se llevaron a cabo las Asambleas Ordinaria y Extraordinaria, ésta última de gran interés por pasar a renovarse parte de los cargos de la Junta Directiva. En representación de los residentes se nombró a la Dra. Velo García, del C.H. Universitario de Pontevedra. Tras el cese de los vocales de Pontevedra y Santiago, fueron elegidos por unanimidad para dichos cargos los Dres. Núñez Fernández y Sánchez Leira, respectivamente. Tal y como se recoge en los estatutos vigentes, la Vicepresidenta, la Dra. Elena Fernández Bouza, fue nombrada Presidenta y a su vez propuso a la Dra. Gómez Buela como nueva Secretaria. El cargo de Vicepresidente, recayó en el Dr. Monte Secades.

Continuando con nombramientos, es de destacar el del Dr. Emilio Casariego como nuevo Presidente de la Sociedad Española de Medicina Interna, así como el del Dr. López Reboiro nuevo vocal de residentes.

Es un orgullo decir que, pese a las dificultades económicas, hemos podido continuar nuestro pequeño homenaje a los socios honoríficos rebajando simbólicamente sus cuotas de inscripción en el Congreso y que continuamos convocando anualmente las becas para la escuela de verano de la SEMI. En esta ocasión, los beneficiarios fueron la Dra. Beceiro Abad y el Dr. Carballo Fernández, ambos del Hospital Clínico de Santiago. Siguiendo con nuestros residentes, un año más la reunión de "os Noveis", celebrada en A Toxa los días 26 y 27 de Junio, agrupó a un número considerable de jóvenes internistas que mostraron su valía ante retos diagnósticos que pondrían en apuros a más de un veterano.

Con la inercia de casi todos los años, durante el 2014 se han seguido sumado nuevos miembros a nuestra Sociedad. Entre ellos, muchos de estos jóvenes repletos de ilusión y energía, además de algún que otro con mayor experiencia, ya que nunca es tarde si la dicha es buena. Si estas líneas trataban inicialmente de ser una especie de diario anual, me gustaría recordar a aquellos que, sin querer, han dejado una línea vacía en nuestras actas y en nosotros mismos. Por la proximidad personal y por el hecho de tratarse de una internista especialmente joven y vital, no puedo menos que destacar, con profunda tristeza, la pérdida de la Dra. Lourdes Vázquez Ledo, residente de Medicina Interna en Santiago, que ha dejado entre nosotros un gran vacío. Su entusiasmo, como el de otros que nos han ido dejando, permanecerá por siempre en nuestra memoria.

Ha sido un placer pertenecer a esta Junta en los últimos dos años. Creo que dignamente hemos aportado nuestro granito de arena para que esta Sociedad siga creciendo y haciéndose más fuerte. Ahora toca dejar paso a nuevas y exitosas propuestas que estoy segura vendrán de la mano de nuestra nueva y primera Presidenta (iya era hora!), así como del resto del equipo. Porque, al fin y al cabo, un gran equipo es lo que somos; remamos en la misma dirección para alcanzar un objetivo común: la excelencia. 